\title{
Understanding the 6 February 2018, Hualien earthquake sequence through catalog compilation
}

\author{
Po-Fei Chen ${ }^{1, *}$, Yen-Ling Chen ${ }^{2}$, Po-Li Su${ }^{1}$, Yi-De Peng ${ }^{1}$, and Li-Fan Chen ${ }^{1}$ \\ ${ }^{1}$ Department of Earth Sciences, National Central University, Taoyuan City, Taiwan \\ ${ }^{2}$ Central Weather Bureau, Taipei City, Taiwan
}

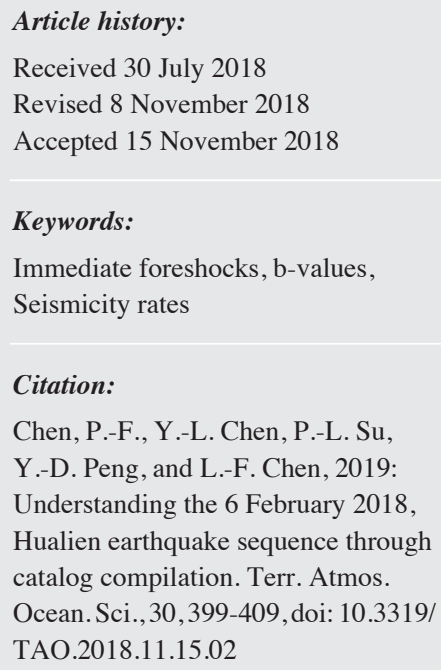

\begin{abstract}
In this study, we compiled the Central Weather Bureau (CWB) data in order to study the Gutenberg-Richter magnitude-frequency slopes (i.e., $b$-values) and seismicity rates of significant earthquake sequences in the area of Hualien. A total of ten events between 1973 and 2018 were selected for analysis. Using time windows $72 \mathrm{~h}$ before and after the main shock, we first examined the existence of detectable foreshocks and then applied the Gutenberg-Richter law and Omori's law to determine the $b$-value and seismicity rate, respectively. The compiled results were used to assess the abnormalities and other characteristics of the 2018 Hualien earthquake for their forecast potential. We concluded that seismicity rates alone are not sufficient to forecast whether a greater main shock is forthcoming. The foreshock sequence of the 2018 Hualien earthquake was characterized by a low $b$-value and a high seismicity rate. Another earthquake with a prominent foreshock sequence occurred in 1990, but it showed a different relationship between the magnitude and the seismicity rate. For both the 1990 and the 2018 Hualien earthquakes, we found that the $b$-values of the foreshocks were lower than those of the respective aftershocks. The $b$-values for earthquake sequences are depressed relative to the background seismicity in the area. The mechanisms proposed for temporal variation in $b$-values are briefly reviewed to explain the observed $b$-value patterns. Finally, we established an empirical relationship with moment magnitude $\left(\mathrm{M}_{\mathrm{w}}\right)$ in order to estimate the spatial range of aftershock distributions in the area of Hualien for shallow earthquakes (hypocenter depth $\leq 20 \mathrm{~km}$ ) with $\mathrm{M}_{\mathrm{w}} \geq 5.3$.
\end{abstract}

\section{INTRODUCTION}

On 6 February 2018, an earthquake with a moment magnitude $\left(\mathrm{M}_{\mathrm{w}}\right)$ of 6.4 hit Hualien, east Taiwan, toppling several buildings and causing more than a dozen casualties (Chang et al. 2019; Chen et al. 2019; Hwang et al. 2019; Wen et al. 2019). Unlike another hazardous $M_{w}=6.4$ earthquake that occurred two years ago in Meinong, Southwest Taiwan (Kanamori et al. 2017; Kuo-Chen et al. 2017; Lee et al. 2017), the 2018 Hualien earthquake was preceded by a prominent foreshock sequence, including a $\mathrm{M}_{\mathrm{w}}=6.1$ event followed by more than 50 events of local magnitude $\mathrm{M}_{\mathrm{L}} \geq$ 3.0 within $12 \mathrm{~h}$ that migrated southwest and upwards (Fig. 1). These events fall into the category of immediate foreshocks, in which earthquakes of smaller magnitude occur a

\footnotetext{
* Corresponding author

E-mail:bob@ncu.edu.tw
}

few hours to days prior to the main shock within a few source dimensions (Dodge et al. 1995). The feasibility of using immediate foreshocks to forecast the ensuing main shock remains an open question, as their causal and statistical relationships remain unclear. The optimistic school attributes foreshocks to a nucleation process, with premonitory slips leading to the dynamic rupture of the main shock (Jones and Molnar 1979). The nucleation process itself, being a shortterm precursor, has been modeled in laboratory experiments (Ohnaka 1992). On the other hand, the pessimistic school attributes foreshocks, main shocks, and aftershocks all to the same triggering dynamic, such that no precursor can be used for the purpose of forecasting (Helmstetter and Sornette 2003; Felzer et al. 2004). The occurrence of the 2018 Hualien earthquake indeed provides an opportunity for answering the question from observational point of view. 
The characteristics that are most often observed in foreshock sequences are changes in the $b$-value and in the seismicity rate. Here, the $b$-value refers to the slope in the magnitude-frequency relationship that was proposed by Gutenberg and Richter (1944):

$\log _{10} N=a-b M$

where $N$ is the number of events with magnitude greater than or equal to magnitude $M$ and $a$ represents the total number of events. Analyzing the world earthquake catalog (1964 $1980, M \geq 4$ ), Molchan and Dmitrieva (1990) found that the $b$-value typically drops to half of the background value during the period beginning a few hours before the main shock.

As for the seismicity rate, the decay of a main shockaftershock sequence follows Omori's law (Omori 1894):

$n(t)=\frac{K}{t+c^{\prime}}$

where $n(t)$ is the number of aftershocks per unit time above a given magnitude, $t$ is the time after the main shock, and $K$ and $c$ are constants. Utsu (1961) introduced a modified version of Omori's law, in which an exponent $(p)$, typically close to 1 , is applied to the denominator. By identifying earthquake clusters from the catalog of the Japan Meteorological Agency, Ogata et al. (1995) found that the 30-day statistical features of foreshocks are well fitted by modified Omori curves with a reverse time span preceding the main shock, with a tendency to spatially converge to the epicenter of the main shock. The prominent foreshock sequence of the 2018 Hualien earthquake allows us to analyze its $b$-value and seismicity rate for comparison.

Hualien and its vicinity in eastern Taiwan are an ideal place for statistically studying the $b$-value and seismicity rate of earthquake sequences, in particular those of foreshocks (Lin 2009). Here, the Philippine Sea and Eurasian plate boundary transitions from offshore easterly subduction to onshore westerly collision (Wu et al. 2009), making Hualien highly seismically active. The average $b$-value in Taiwan is about 1.1, as determined from shallow earthquakes (hypocenter depth $<40 \mathrm{~km}$ ) that occurred during the period from 1973 to 1985 (Wang 1988). Please refer to Wang et al. (2015) for a comprehensive review of $b$-value studies of earthquakes in the region of Taiwan. As for foreshocks in the region of Taiwan, Lin (2009) examined the Central Weather Bureau (CWB) catalog records between 1990 and 2004 and found ten earthquake sequences with felt foreshocks $\left(\mathrm{M}_{\mathrm{L}} \geq\right.$ 4.0), mostly on the heterogeneous crust of east Taiwan. The seismicity rates of these foreshock sequences, unlike that of the 2018 Hualien earthquake, tend to be lower than that of a typical main shock-aftershock sequence.
In this study, our aim is to examine the suitability of the 2018 Hualien earthquake for forecasting potential, by analyzing the data for any abnormality. The abnormality must be assessed in comparison with other earthquake sequences in the Hualien area. To this end, we compiled data from the CWB catalog in order to investigate the characteristics of significant earthquake sequences in the Hualien area. First, we examined the existence of detectable foreshocks in each case. Secondly, we determined the $b$-value and seismicity rate for the main shock and foreshock sequence (if any). The compiled results were compared with those of the 2018 Hualien earthquake. We focused on $72 \mathrm{~h}$ time windows immediately before and after the main shock. The time windows used is for analysis of short-term precursors, which differs from those studies that focus on long-term precursors (e.g., Chen et al. 2017; Wen and Chen 2017).

\section{DATA AND METHODS}

The CWB catalog is relatively complete for earthquakes in Taiwan and its vicinity since the 1970s, beginning with the installation of Taiwan's Telemetered Seismographic Network (TTSN) (Wang 1989). Using the TTSN, the sizes of earthquakes were routinely measured as duration magnitude $\left(\mathrm{M}_{\mathrm{D}}\right)$. Since 1991, with the deployment of the CWB Seismic Network (CWBSN) in Taiwan, the local magnitude $\left(\mathrm{M}_{\mathrm{L}}\right)$ of earthquakes has been determined by simulating WoodAnderson seismograms using three-component short-period CWBSN seismographs. The relationship used to convert $M_{D}$ into $\mathrm{M}_{\mathrm{L}}$ was established for earthquakes in the TTSN period (Shin 1993). The CWBSN operated in trigger mode until 1994, when it switched to continuous mode, resulting in the improvement in monitoring small events. The magnitude of completeness $\left(\mathrm{M}_{\mathrm{C}}\right)$ before 1994 was 2.5 as determined by our frequency-magnitude analysis and that after 1994 was 2.0 as determined by Wu and Chiao (2006).

We scanned the CWB catalog (since 1973) for the Hualien area as bounded by the 23.5 and $24.7^{\circ} \mathrm{N}$ parallels and the 121.2 and $122.2^{\circ} \mathrm{E}$ meridians (Fig. 2). We selected only those sequences with more than ten events of $\mathrm{M}_{\mathrm{L}} \geq$ 4.0 within $72 \mathrm{~h}$, and the maximum $\mathrm{M}_{\mathrm{L}}$ event was treated as the main shock. A search was conducted again on each sequence with time periods limited to within $72 \mathrm{~h}$ before and after the main shock, resulting in sequences spatially clustering around the main shock and a few outliers distributed relatively far away from the main shock. For each sequence, we used events with $\mathrm{M}_{\mathrm{L}} \geq 3.0$ to estimate the spatial distribution. The reason why $\mathrm{M}_{\mathrm{L}}=3.0$ was used as a threshold value is practical: Smaller events are generally not reported in real time by the CWB.

For each sequence, we discarded outliers as follows. First, the average latitude, longitude, and depth were taken as a center from which to calculate distances of events in the same sequence. Then, we derived the average distance 


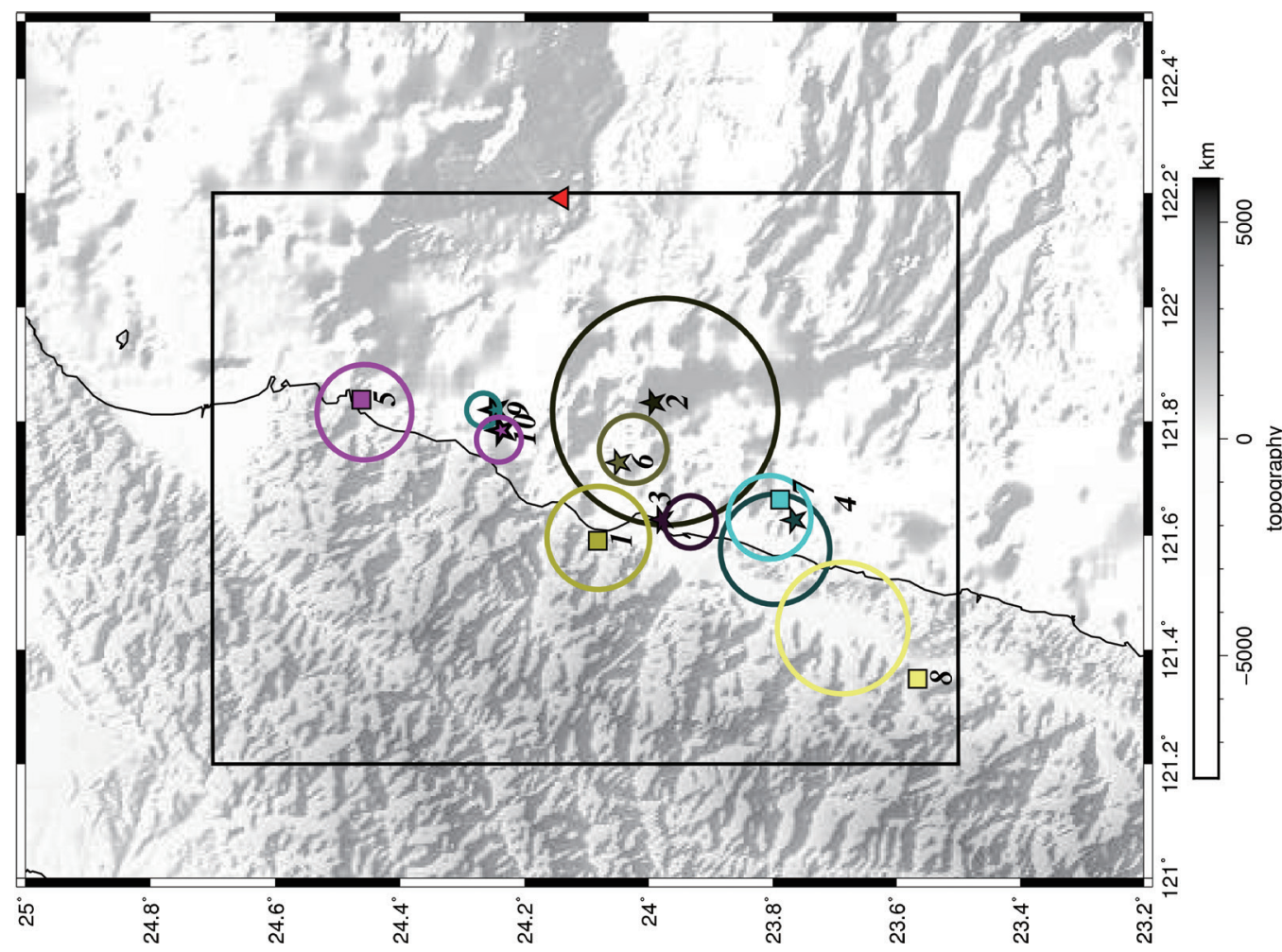

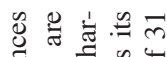

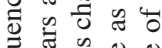

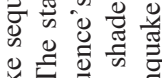

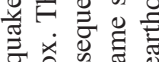

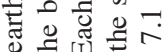

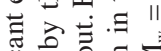

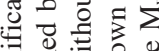

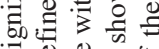

की

讨

Ð

ते

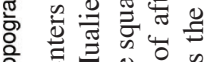

可

훙엄

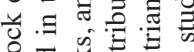

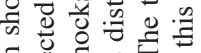

园

\& 0 过

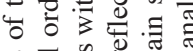

ปี.

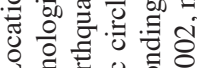

i

ํ.

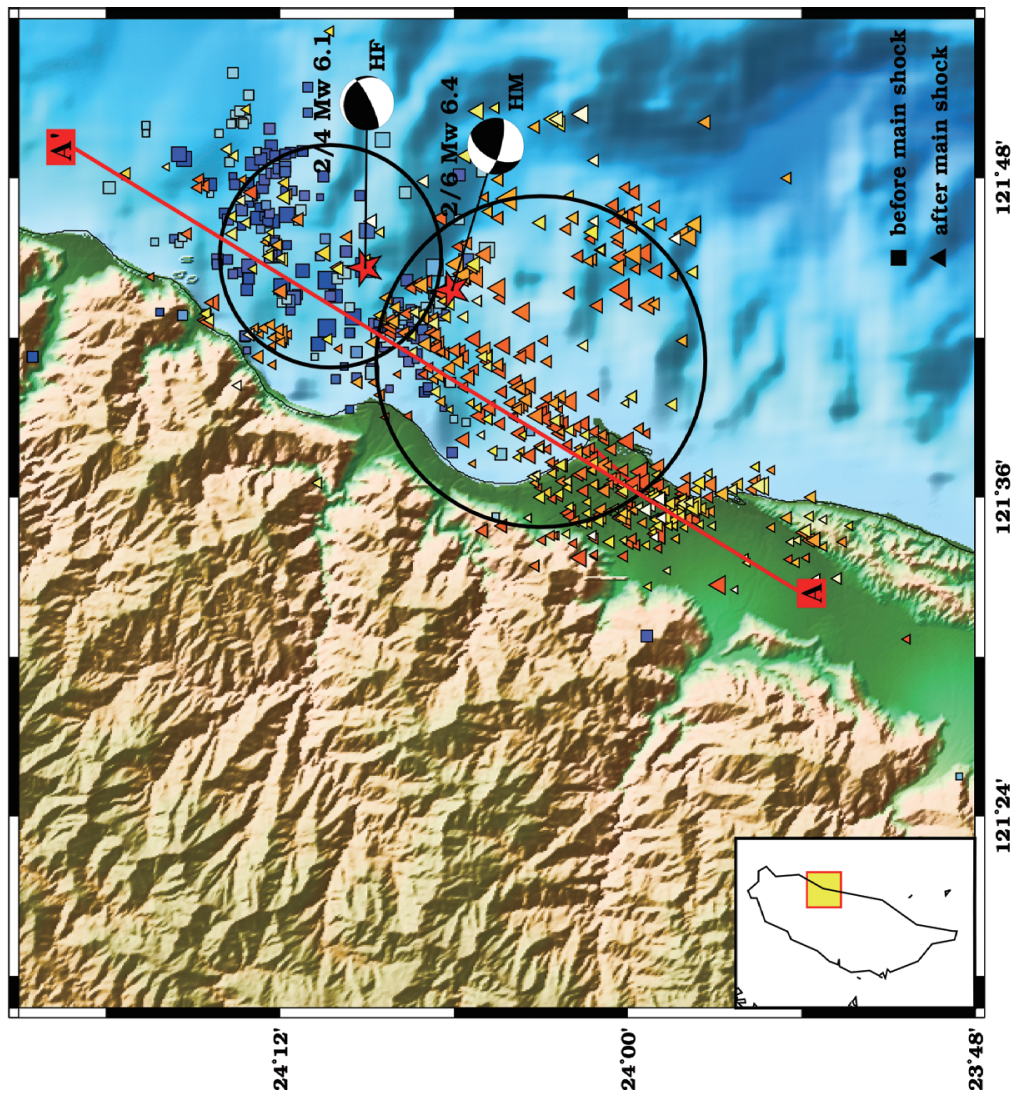

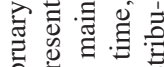

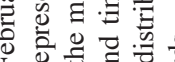

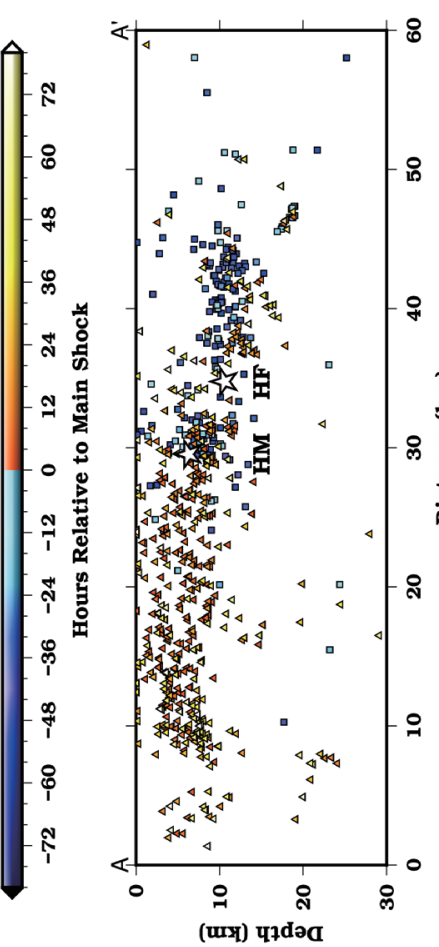

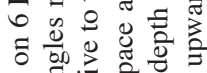

o. .

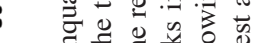

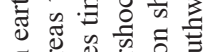

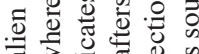

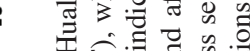

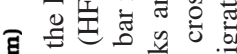

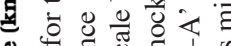

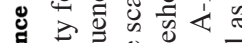

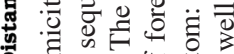
量 क्ष

ᄃ 8

国

E

$\forall$ 品

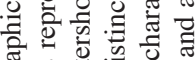

品

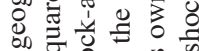

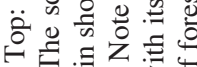

$-\infty$ 开 30

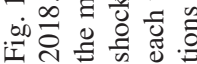


and standard deviation over all events in a sequence. Those events occurring more than twice the standard deviation beyond the average distance were discarded. This procedure was conducted twice in order to avoid the effects of faraway outliers, with the resulting average distance taken as the characteristic radius $(R)$. Since $95 \%$ of statistically relevant events should occur within two standard deviations of $R$, the above procedure accordingly should cover $90 \%$ of the events in the sequence. We thus deem $R$ as a fair measurement for the spatial distribution of aftershocks, at least for the first $72 \mathrm{~h}$. A total of 10 sequences (Table 1, Fig. 2) were thereby selected and ordered chronologically. We excluded the 1999 Chi-Chi earthquake sequence owing to the lack of event clustering, as well as the $\mathrm{M}_{\mathrm{w}}=7.1$ earthquake of 31 March 2002, located very near to the edge of the study area. For the 2018 Hualien earthquake, we used HF to refer to the foreshock sequence and HM to refer to the main shock sequence. We treated HF and HM as two individual clusters in order to determine each cluster's characteristic radius $(R)$ (Fig. 1). The total number of discarded events is 60 for one-cluster treatment and 25 for two-cluster treatment. This substantial reduction of discarded events justified the spatial distinction of $\mathrm{HF}$ and $\mathrm{HM}$.

We adopted $\mathrm{M}_{\mathrm{w}}$ in the Global Centroid Moment Tensor catalog (GCMT, Dziewonski et al. 1983) for the main shocks in Table 1 and for the 2018 Hualien earthquake (HF and $\mathrm{HM}$ ). Conversion from $\mathrm{M}_{\mathrm{L}}$ into $\mathrm{M}_{\mathrm{w}}$ is necessary to estimate the cumulative seismic moment release for historical records measured as $\mathrm{M}_{\mathrm{L}}$. Notably, there exists some discrepancy between $\mathrm{M}_{\mathrm{L}}$ in the CWB catalog and $\mathrm{M}_{\mathrm{w}}$ in the GCMT catalog for the same sequences. Due to the fact that this discrepancy is not unidirectional but rather found to point in different directions for different sequences, it cannot be due solely to the saturation of $\mathrm{M}_{\mathrm{L}}$. An empirical relationship of $\mathrm{M}_{\mathrm{L}}-$ to- $\mathrm{M}_{\mathrm{w}}$ conversion was therefore derived by linear regression using events within the study region as recorded by both catalogs (Fig. 3). For each sequence, the hourly cumulative moment release was summed, and the hourly number of events with $\mathrm{M}_{\mathrm{L}} \geq 3.0$ was counted, using the time of the main shock as a reference, and marked as zero (Fig. 4). By counting the number of aftershocks with $\mathrm{M}_{\mathrm{L}} \geq 3.0$ every $12 \mathrm{~h}$ through the $72 \mathrm{~h}$ span, we were able to estimate the best-fit value of the constant $K$ in Eq. (2), since it is proportional to the seismicity rate. These six sequential data points were used for fitting with nonlinear least-squares regression using MATLAB software (MathWorks, Natick, MA, USA) for the determination of $K$ and $c$ in Eq. (2). A frequencymagnitude analysis was also conducted to determine the $b$ values of earthquakes within $72 \mathrm{~h}$ after the main shock. We adopted a simple linear regression to fit between $\mathrm{M}_{\mathrm{L}}$ and the cumulative number of events greater than $\mathrm{M}_{\mathrm{L}}$ (Bevington 1969). We visually selected the range of $M_{L}$ for fitting so that the resulting correlation coefficient would be greater than 0.99 (Table 1).

\section{RESULTS}

Among the histograms of the 10 selected sequences (Figs. 4, S1, and S2), six exhibited immediate foreshocks (Sequences 2, 3, 4, 6, 9, and 10). Most of the immediate foreshocks were distributed sporadically in time, concurring with the previously observed foreshock sequence deficiency (Lin 2009). However, the 1990 event (Sequence 4) also exhibited a prominent foreshock sequence preceding the main shock, similar to that of the Hualien earthquake (Fig. 4). Here, we refer to the 1990 foreshock sequence as $4 \mathrm{~F}$ and the main shock sequence as $4 \mathrm{M}$.

Figures 5 and 6 show the $K$-values and $b$-values, respectively, of each sequence, including all 11 true main shock sequences as well as the $4 \mathrm{~F}$ and $4 \mathrm{M}$ foreshock sequences. Due to the seismicity patterns, the $K$-value or the $b$-value could not be reasonably determined for every sequence. For the $K$-value, the aftershock seismicity in Sequences 1 and 2 did not strictly decay with time, so the regression for each yielded no reliable solutions (Fig. 5). For the $b$-value, the frequency-magnitude distribution of Sequence 6 suffered from severe undersampling, preventing confident fitting (Fig. 6). For all other sequences, Fig. 7 shows the results on the $b$ - $K$-plane, with different symbols for different ranges of earthquake depths. We analyzed these overall patterns in order to assess the characteristics of the 2018 Hualien earthquake.

Across these 10 sequences, the composite distribution of $K$ coupled with earthquake size and depth appears to show three groupings - high $K$, middle $K$, and low $K$-with divisions at $K$-values of roughly $K=15$ and $K=35$ (Fig. 7). Only those sequences with $\mathrm{M}_{\mathrm{w}} \geq 6.3$ and shallow depth $(0-10 \mathrm{~km})$ are in the high $K$ group (Sequences 4M, 5, and HM). Those sequences with $\mathrm{M}_{\mathrm{w}} \leq 5.6$ (Sequences 3 and 10) tended to be low in the $K$-values, regardless of the depth range. However, the $2015 \mathrm{M}_{\mathrm{w}}=5.3$ earthquake (Sequence 9) was an exception, grouping in the middle $K$ with its high seismicity rate of aftershocks continuing for at least $24 \mathrm{~h}$ (Figs. 5, S2). Earthquake size constitutes a necessary rather than a sufficient condition for high seismicity rates, as exemplified by three $\mathrm{M}_{\mathrm{w}} \geq 6.3$ events (Sequences $4 \mathrm{~F}, 7$, and 8) in the low $K$ group. Among these, the $43.8 \mathrm{~km}$ depth of Sequence 7 is surely responsible for its low $K$, whereas the $15.0 \mathrm{~km}$ depth of Sequence 8 , being beyond the $10 \mathrm{~km}$ threshold, may play a similar role. However, the low $K$-value exhibited by foreshock sequence $4 \mathrm{~F}\left(\mathrm{M}_{\mathrm{w}}=6.3\right.$ at a $2.8 \mathrm{~km}$ depth $)$ is surprising and may represent another example of foreshock sequence deficiency. In contrast, the foreshock Sequence HF from the 2018 Hualien earthquake $\left(\mathrm{M}_{\mathrm{w}}=6.1\right.$ at a $10.6 \mathrm{~km}$ depth $)$ shows a middle $K$-value. Looking at Sequences $9,4 \mathrm{~F}$, and HF together, we conclude that the seismicity rate alone is not sufficient to tell an immediate foreshock sequence from a main shock-aftershock sequence.

However, if we combine these $K$-value results with the 
Table 1. Source parameters of earthquake sequences. $\Delta \mathrm{M}_{\mathrm{L}}$ represents the $\mathrm{M}_{\mathrm{L}}$ difference between the main shock and the largest aftershock. The penultimate column is the $\mathrm{M}_{\mathrm{L}}$ range for $b$-value determination. The final column is for foreshocks (true or false). See the text for other parameters. The numbers in parentheses represent the standard deviation.

\begin{tabular}{|c|c|c|c|c|c|c|c|c|c|c|c|}
\hline No. & Date & Lat. & Lon. & Dep. (km) & $\mathbf{M}_{\mathrm{L}} / \mathbf{M}_{\mathrm{w}}$ & $\Delta \mathrm{M}_{\mathrm{L}}$ & $R(\mathbf{k m})$ & $K$ & $b$ & $\begin{array}{l}\mathbf{M}_{\mathbf{L}}^{\min } \\
\mathbf{M}_{\mathbf{L}}^{\max } \\
\end{array}$ & $P$ \\
\hline 1 & $1986 / 05 / 20$ & 24.082 & 121.591 & 15.8 & $6.5 / 6.2$ & 0.7 & $\begin{array}{c}9.2 \\
(6.2) \\
\end{array}$ & NA & $\begin{array}{c}0.86 \\
(0.02)\end{array}$ & $\begin{array}{l}2.3 \\
4.2 \\
\end{array}$ & $\mathrm{~F}$ \\
\hline 2 & $1986 / 11 / 14$ & 23.992 & 121.833 & 15.0 & $6.8 / 7.3$ & 0.5 & $\begin{array}{l}20.2 \\
(9.8) \\
\end{array}$ & $\begin{array}{c}660 \\
(1128) \\
\end{array}$ & $\begin{array}{c}0.89 \\
(0.01) \\
\end{array}$ & $\begin{array}{l}2.7 \\
5.7 \\
\end{array}$ & $\mathrm{~T}$ \\
\hline 3 & $1988 / 04 / 07$ & 23.979 & 121.628 & 1.4 & $5.7 / 5.6$ & 0.6 & $\begin{array}{c}4.7 \\
(3.3)\end{array}$ & $\begin{array}{c}5 \\
(3)\end{array}$ & $\begin{array}{c}0.96 \\
(0.03) \\
\end{array}$ & $\begin{array}{l}3.0 \\
4.5 \\
\end{array}$ & $\mathrm{~T}$ \\
\hline $4 \mathrm{~F}$ & $1990 / 12 / 13$ & 23.879 & 121.548 & 2.8 & $6.5 / 6.3$ & 1.8 & $\begin{array}{c}9.8 \\
(5.1)\end{array}$ & $\begin{array}{c}9 \\
(11)\end{array}$ & $\begin{array}{c}0.85 \\
(0.02)\end{array}$ & $\begin{array}{l}2.9 \\
4.7 \\
\end{array}$ & $\mathrm{~T}$ \\
\hline $4 \mathrm{M}$ & $1990 / 12 / 13$ & 23.765 & 121.627 & 1.3 & $6.7 / 6.3$ & 1.5 & $\begin{array}{c}9.8 \\
(5.1) \\
\end{array}$ & $\begin{array}{c}61 \\
(27) \\
\end{array}$ & $\begin{array}{c}0.90 \\
(0.03)\end{array}$ & $\begin{array}{l}2.7 \\
5.1 \\
\end{array}$ & $\mathrm{~T}$ \\
\hline 5 & $1994 / 06 / 05$ & 24.462 & 121.838 & 5.3 & $6.5 / 6.3$ & 1.4 & $\begin{array}{c}8.5 \\
(5.3) \\
\end{array}$ & $\begin{array}{c}38 \\
(12) \\
\end{array}$ & $\begin{array}{c}0.92 \\
(0.05) \\
\end{array}$ & $\begin{array}{l}2.0 \\
5.1 \\
\end{array}$ & $\mathrm{~F}$ \\
\hline 6 & $2000 / 07 / 14$ & 24.048 & 121.728 & 7.2 & $5.7 / 5.4$ & 0.6 & $\begin{array}{c}6.0 \\
(3.8) \\
\end{array}$ & $\begin{array}{c}1 \\
(1)\end{array}$ & NA & NA & $\mathrm{T}$ \\
\hline 7 & $2009 / 12 / 19$ & 23.788 & 121.663 & 43.8 & $6.9 / 6.4$ & 2.1 & $\begin{array}{c}7.4 \\
(5.2) \\
\end{array}$ & $\begin{array}{c}8 \\
(9) \\
\end{array}$ & $\begin{array}{c}0.82 \\
(0.01)\end{array}$ & $\begin{array}{l}2.2 \\
4.8 \\
\end{array}$ & $\mathrm{~F}$ \\
\hline 8 & $2013 / 10 / 31$ & 23.566 & 121.349 & 15.0 & $6.4 / 6.3$ & 1.3 & $\begin{array}{c}11.7 \\
(11.0)\end{array}$ & $\begin{array}{c}5 \\
(8) \\
\end{array}$ & $\begin{array}{c}0.66 \\
(0.01)\end{array}$ & $\begin{array}{l}1.5 \\
4.6 \\
\end{array}$ & $\mathrm{~F}$ \\
\hline 9 & $2015 / 09 / 15$ & 24.248 & 121.820 & 19.8 & $5.7 / 5.3$ & 0.1 & $\begin{array}{c}3.0 \\
(1.5) \\
\end{array}$ & $\begin{array}{c}28 \\
(34) \\
\end{array}$ & $\begin{array}{c}0.81 \\
(0.06) \\
\end{array}$ & $\begin{array}{l}1.5 \\
4.6 \\
\end{array}$ & $\mathrm{~T}$ \\
\hline 10 & $2016 / 04 / 27$ & 24.237 & 121.784 & 11.9 & $5.7 / 5.5$ & 0.6 & $\begin{array}{c}4.0 \\
(2.2) \\
\end{array}$ & $\begin{array}{c}7 \\
(12) \\
\end{array}$ & $\begin{array}{c}0.75 \\
(0.01) \\
\end{array}$ & $\begin{array}{l}1.5 \\
4.6 \\
\end{array}$ & $\mathrm{~T}$ \\
\hline $\mathrm{HF}$ & $2018 / 02 / 04$ & 24.151 & 121.744 & 10.6 & $5.9 / 6.1$ & 0.6 & $\begin{array}{c}7.1 \\
(2.9)\end{array}$ & $\begin{array}{c}22 \\
(15)\end{array}$ & $\begin{array}{c}0.63 \\
(0.01)\end{array}$ & $\begin{array}{l}2.5 \\
4.8 \\
\end{array}$ & $\mathrm{~T}$ \\
\hline $\mathrm{HM}$ & $2018 / 02 / 06$ & 24.101 & 121.730 & 6.3 & $6.3 / 6.4$ & 0.5 & \begin{tabular}{|l|}
10.5 \\
$(5.1)$ \\
\end{tabular} & $\begin{array}{c}62 \\
(29) \\
\end{array}$ & $\begin{array}{c}0.68 \\
(0.02) \\
\end{array}$ & $\begin{array}{l}2.3 \\
5.0 \\
\end{array}$ & $\mathrm{~T}$ \\
\hline
\end{tabular}

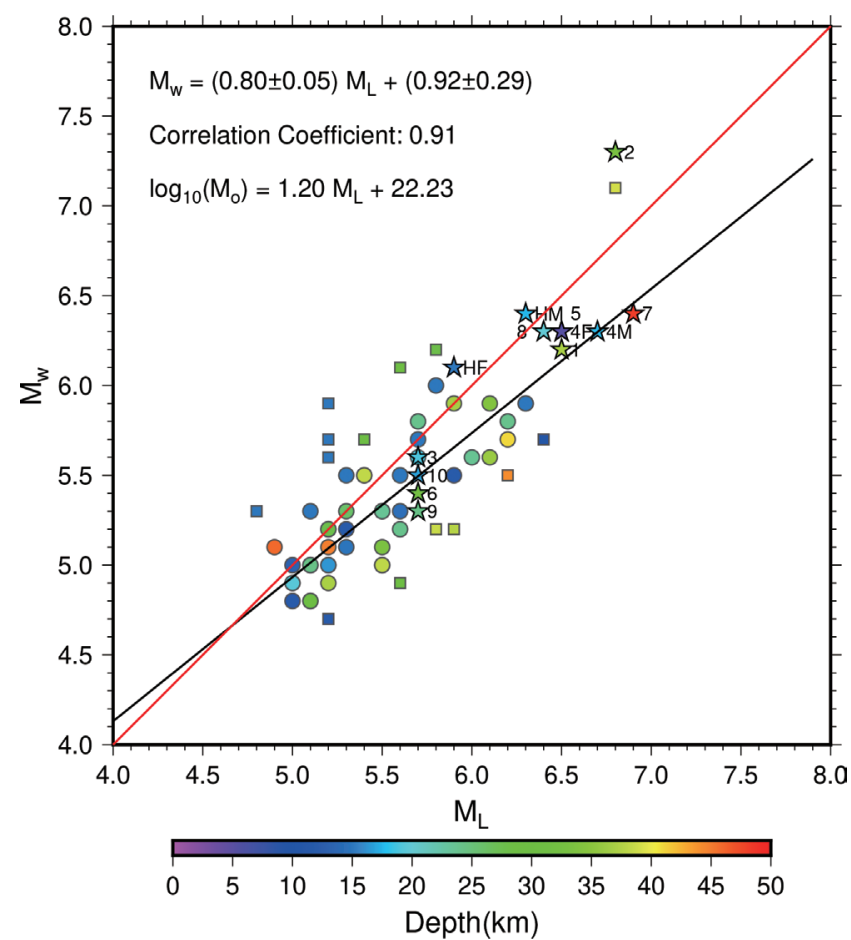

Fig. 3. Regression (black line) of $\mathrm{M}_{\mathrm{L}}-\mathrm{M}_{\mathrm{w}}$ relationships using earthquakes recorded in both the CWB and the GCMT catalogs, followed by a conversion from $\mathrm{M}_{\mathrm{L}}$ to seismic moment $\left(\mathrm{M}_{\mathrm{o}}\right.$ in dyne-cm). Square points were not used for regression. The stars are events in Table 1 with numbers indicated. The square with $M_{w}=7.1$ is the 31 March 2002, earthquake. The red line represents $M_{L}=M_{w}$, for reference. Note that earthquakes with a depth greater than $20 \mathrm{~km}$ tend to fall to the right of the red line $\left(\mathrm{M}_{\mathrm{L}} \geq \mathrm{M}_{\mathrm{w}}\right)$. 

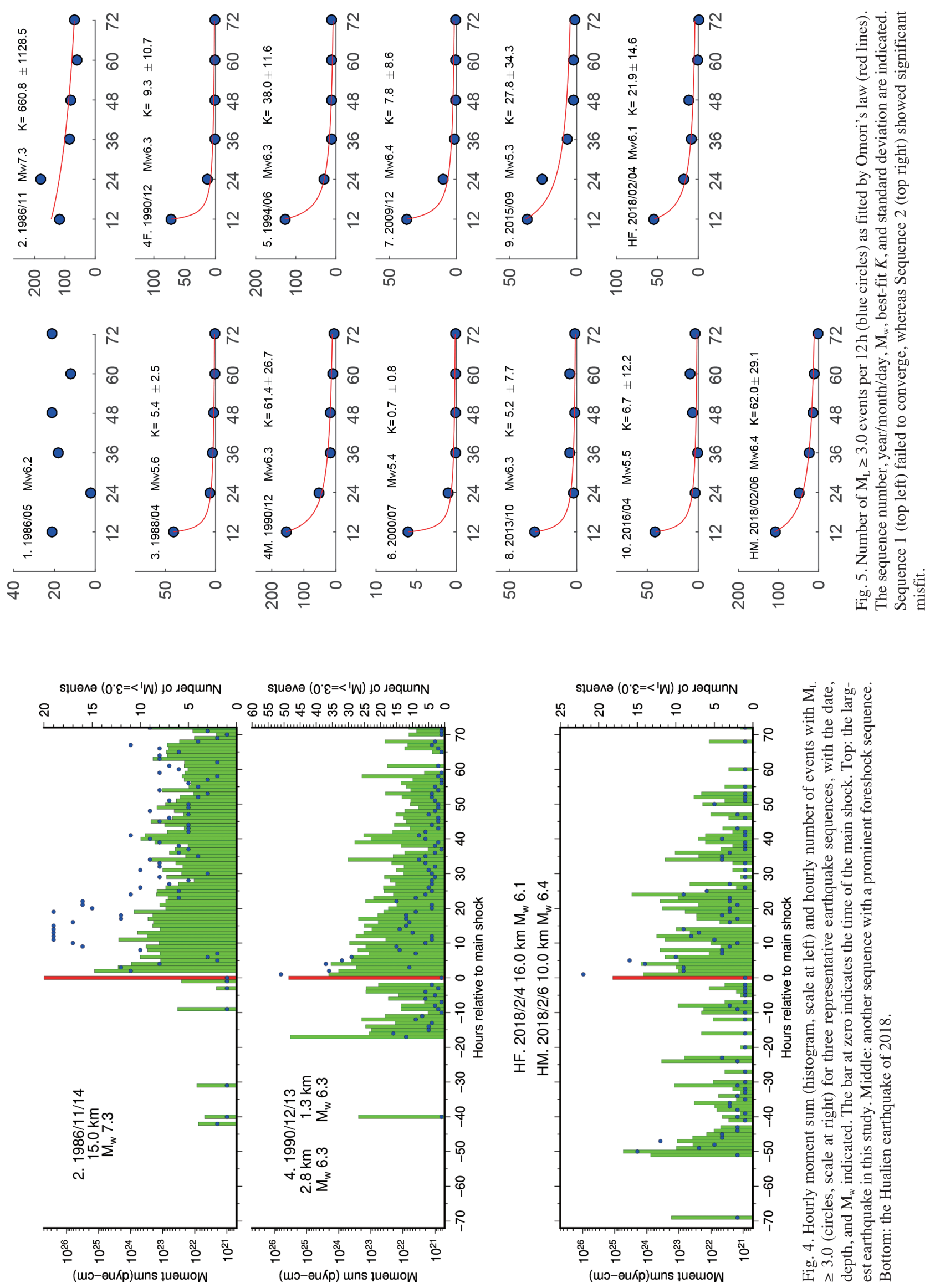

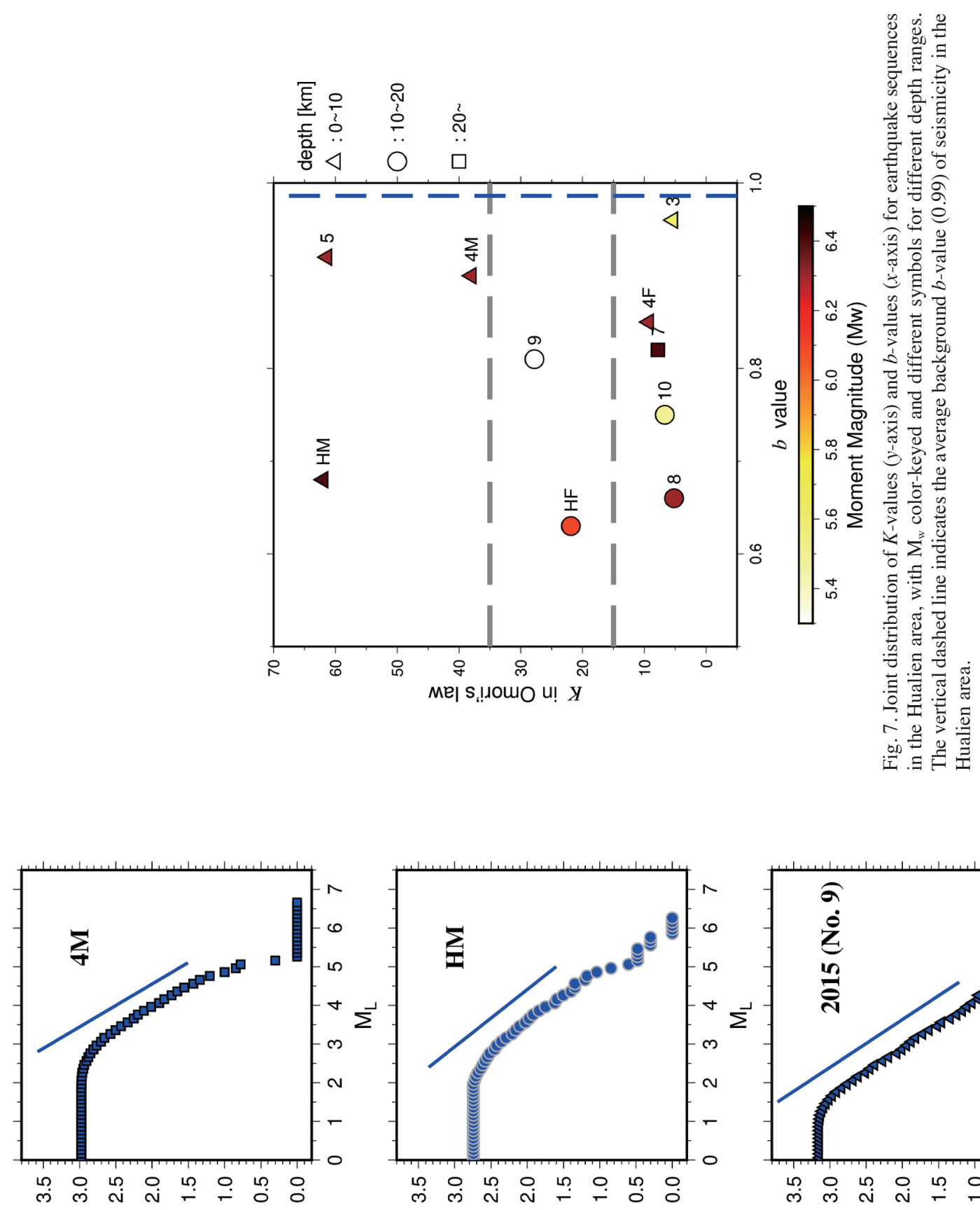

$(\mathrm{N})^{0+60}$

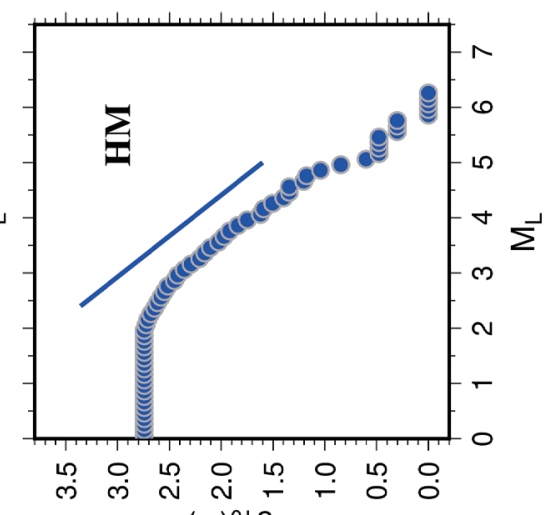

$(N)^{0 !} 6$ ol

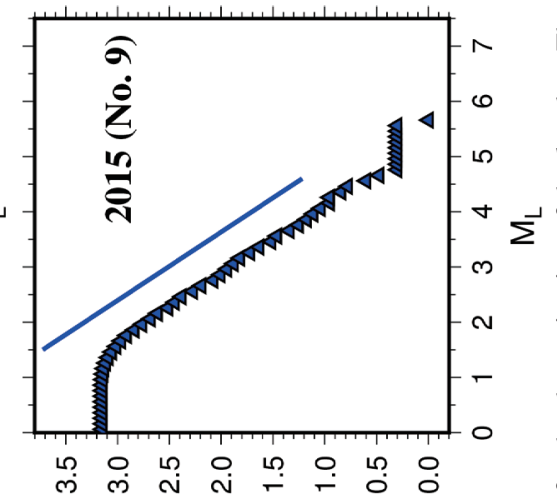

导䒠官

$\stackrel{0}{3}$

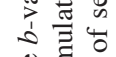

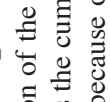

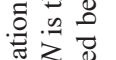

悬首

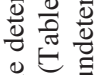

$\underset{000}{\oplus} \equiv$

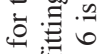

$(\mathrm{N})^{0+6}$ 이

进

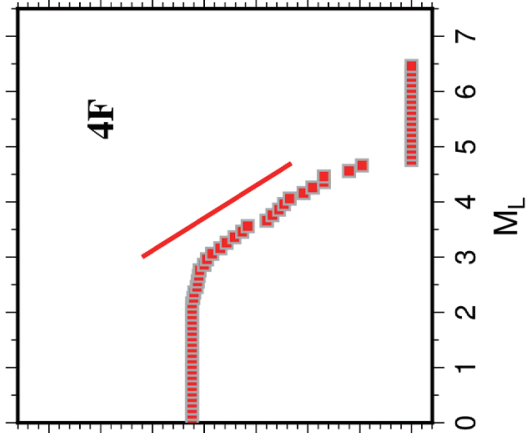

மீ) $(\mathrm{N})^{01} \mathrm{~b}$ 이

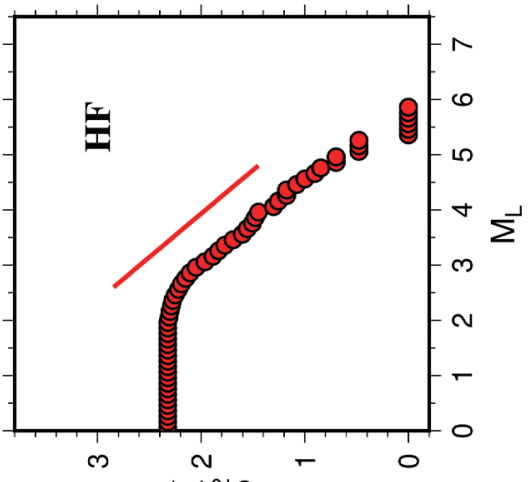

$(N)^{0+6}$ ol

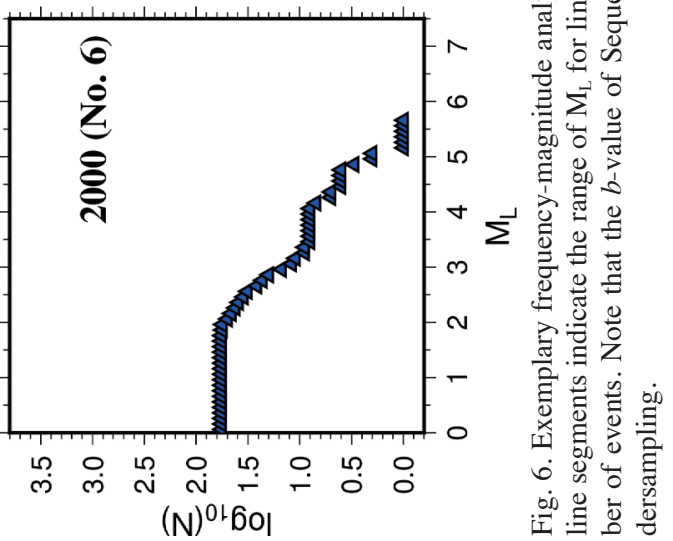


$b$-value results, the 2018 Hualien earthquake can be shown to have presented distinctive features not observed in previous earthquake sequences in the area. We estimated the long-term average $b$-value for overall seismicity in the area to be $0.99 \pm 0.01$, comparable to the $b$-value of 1.1 in previous studies. On the other hand, the $b$-values for seismicity within $72 \mathrm{~h}$ of earthquake main shocks tended to be smaller than the long-term average, ranging from 0.63 to 0.96 . The $b$-values of the 2018 Hualien earthquake sequences, both $\mathrm{HF}$ and HM, are among the lowest of all, suggesting a relatively large ratio of big events to small events. As regards the forecast potential, the foreshock sequence of the 2018 Hualien earthquake did exhibit a high seismicity rate with events of relatively large magnitude. These characteristics are distinct and unprecedented compared to other sequences previously recorded in the area. Whether these characteristics constitute a sufficient condition for predicting an ensuing main shock remains to be explored.

Finally, we found that the characteristic spatial radius $R$ of the earthquake sequences is generally linearly proportional to the size of the main shock for shallow earthquakes $(\leq 20 \mathrm{~km})$. Sequence 7 , the only lower crust event at a $43.8 \mathrm{~km}$ depth, has a relatively low $R$ and was excluded from the linear regression analysis. Thus, an empirical relationship was established (Fig. 8) between $R$ and $\mathrm{M}_{\mathrm{w}}$ :

$R=(7.80 \pm 0.82) \mathrm{M}_{\mathrm{w}}-(38.68 \pm 4.98)$

This relationship is mostly applicable to spatial range estimates for aftershock distributions for shallow earthquakes $(\leq 20 \mathrm{~km})$ with $\mathrm{M}_{\mathrm{w}} \geq 5.3$ in the Hualien area.

\section{DISCUSSION}

Differences in the $b$-values between foreshock and aftershock sequences have been investigated as a potential precursor (Knopoff et al. 1982). The statistical analysis of regional and global earthquake data shows a typical drop in the $b$-values for immediate foreshocks relative to long-term seismicity (Molchan et al. 1999). Here, we examined the change in the $b$-value for Sequence 4F versus Sequence 4M and for Sequence HF versus Sequence HM. In the frequency-magnitude analysis (Fig. 9), the total number of events for foreshock and aftershock sequences was normalized by moving them into the same horizon. The normalized results show foreshocks extending to higher $\mathrm{M}_{\mathrm{L}}$ values than the corresponding aftershocks. This finding suggests that relatively low $b$-values of foreshock sequences are genuine and not artificially diminished by the measurement methods. However, the mechanisms behind such changes in the $b$-value are still not clear.

In order to explain the low $b$-value of Sequence HF, we invoked causal mechanisms proposed for long-term temporal variations in $b$-values around the main shock. These mechanisms have been supported either by experiments on fracture mechanics (Main et al. 1989) or by simulations of dynamical spring-slider models (Wang 1995). For the former, according to laboratory acoustic emission data, $b$-values are inversely correlated with the resistance to fracture (or the stress intensity factor). Resistance to fracture is in turn proportional to the product of the remotely applied stress and the square root of the length of the propagating crack or flaw (Meredith and Atkinson 1983). In anelastic failure model, the short-term drop in the $b$-value observed in the immediate foreshock sequence during the strain softening phase can be explained as a result of critical coalescence of neighboring microcracks before dynamic failure (Main et al. 1989). For the latter, Wang (1995) obtained power-law correlations between the $b$-value and the stiffness ratio of the system. Wang (2012) further deduced that, with increasing the $P$-wave velocity of the fault zone material, the $b$-value drops. The temporal variation in the $b$-value during an earthquake cycle would then be related to the percentage of water saturation in the fault zone, resulting in depressed $b$-values during the wait time before the main shock (Wang 2016).

The strategy of focusing on major earthquake sequences using criteria of more than $10 \mathrm{M}_{\mathrm{L}} \geq 4.0$ events within $72 \mathrm{~h}$ was motivated by the pattern of Sequence HF. This approach ends up selecting all earthquakes with $\mathrm{M}_{\mathrm{w}} \geq 6.0$ and depth $\leq 20 \mathrm{~km}$ (Fig. 3). Earthquakes with depths greater than $20 \mathrm{~km}$ tend to have greater $M_{L}$ than $M_{w}$ (Fig. 3) and relatively low seismicity rates. This explains why some events with $\mathrm{M}_{\mathrm{L}}$ greater than 6.0 and depths greater than $20 \mathrm{~km}$ were not selected by the criteria. However, the strategy here is valid in terms of seismic hazard mitigations, since at the same magnitude shallow earthquakes will cause greater damage.

\section{CONCLUSIONS}

By distinguishing significant earthquake sequences in the Hualien area and investigating their seismicity rates and $b$-values, we concluded that the seismicity rate alone is not sufficient to distinguish an immediate foreshock sequence from a main shock-aftershock sequence. The foreshock sequence of the 2018 Hualien earthquake is characterized by both a high seismicity rate and a low $b$-value, a combination unprecedented in the Hualien area. Another earthquake with a prominent foreshock sequence occurred in 1990, but the seismicity rate was not particularly high given $\mathrm{M}_{\mathrm{w}}=6.3$ of that event. In both the 1990 and the 2018 Hualien earthquakes, the $b$-values were lower for the foreshock sequence than for the aftershock sequence. An empirical relationship defined between the spatial range $R$ of aftershocks and earthquake size $\mathrm{M}_{\mathrm{w}}$ shows that $R=(7.80 \pm 0.82) \mathrm{M}_{\mathrm{w}}-(38.68$ $\pm 4.98)$. This relationship is mostly applicable to shallow earthquakes $(\leq 20 \mathrm{~km})$ with $\mathrm{M}_{\mathrm{w}} \geq 5.3$ in the Hualien area. 


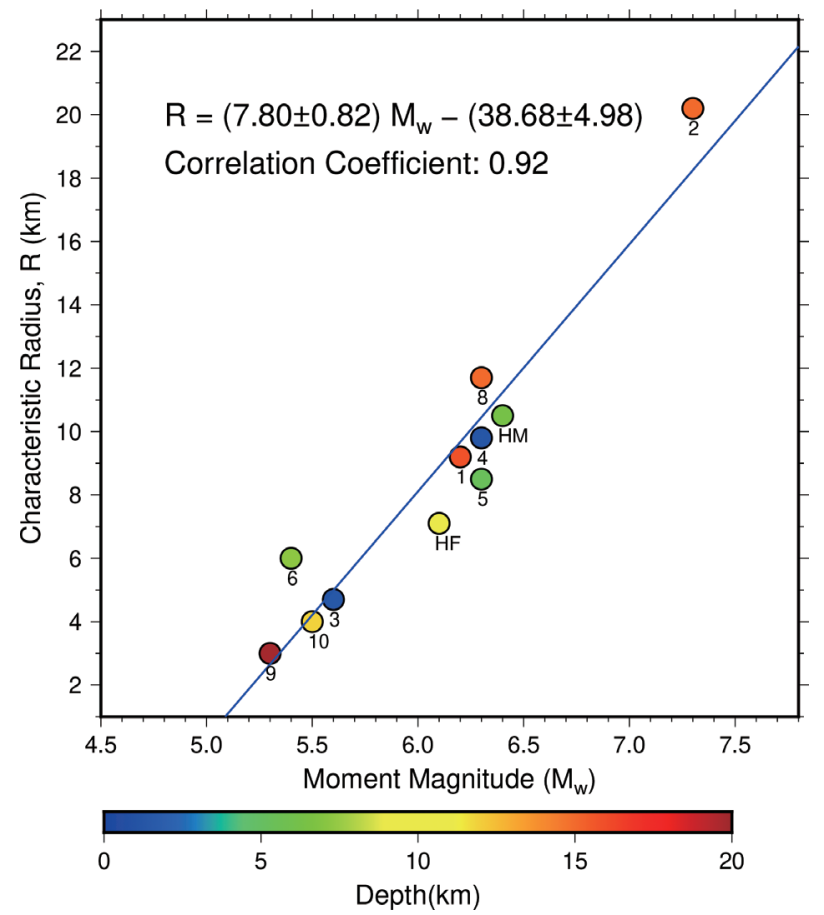

Fig. 8. Linear regression of the characteristic radius and moment magnitude $\left(\mathrm{M}_{\mathrm{w}}\right)$ of earthquake sequences. The empirical relationship is applicable to shallow earthquakes ( $\leq 20 \mathrm{~km})$ with $\mathrm{M}_{\mathrm{w}} \geq 5.3$.

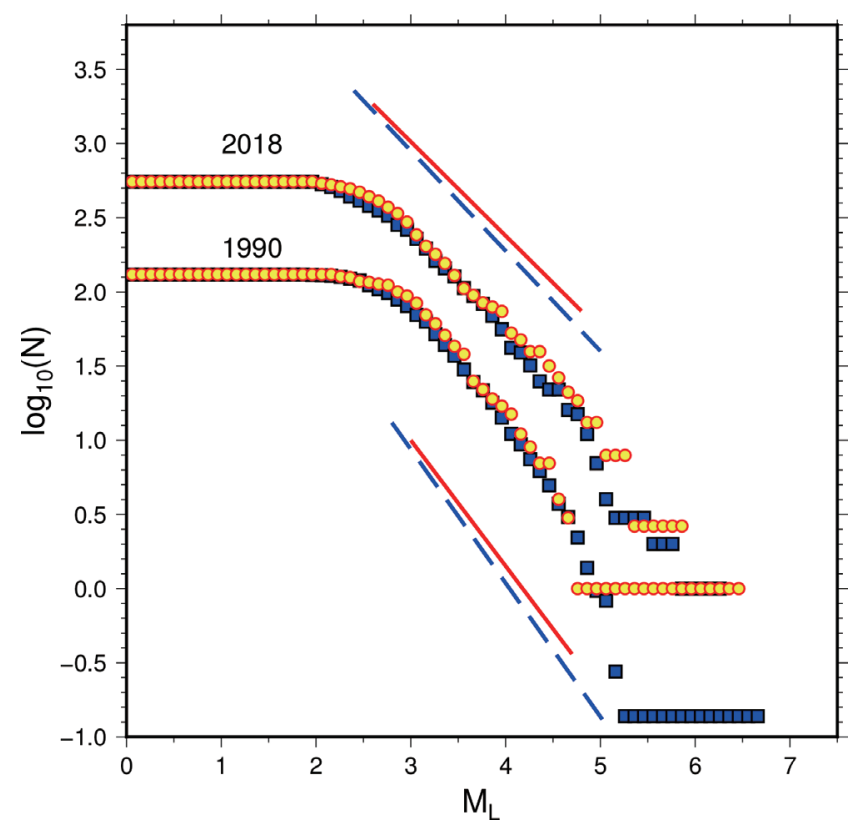

Fig. 9. Frequency-magnitude distributions of foreshock (circles) and aftershock (squares) sequences for the 1990 and 2018 Hualien earthquakes, with the total number normalized between each earthquake's foreshocks and aftershocks. The line segments indicate the range of $\mathrm{M}_{\mathrm{L}}$ for inverting $b$-values. Note that the circles are distributed to the right of the squares, suggesting a genuinely depressed $b$-value for foreshock sequences. 
Acknowledgements We greatly appreciate the valuable suggestions provided by two anonymous reviewers. This work was supported by the Taiwan Earthquake Research Center (TEC) funded through Ministry of Science and Technology (MOST) of Taiwan with Grant Number 1062116-M-008-004 and by the Central Weather Bureau with Grant Number MOTC-CWB-107-E-03. The TEC contribution number for this article is 00150. Figures were prepared with Generic Mapping Tools (Wessel and Smith 1998).

\section{REFERENCES}

Bevington, P. R., 1969: Data Reduction and Error Analysis for the Physical Sciences, McGraw-Hill, New York, $336 \mathrm{pp}$.

Chang, Y.-H., S.-H. Hung, and Y.-L. Chen, 2019: A fast algorithm for automatic phase picker and event location: Application to the 2018 Hualien earthquake sequences. Terr. Atmos. Ocean. Sci., 30, 435-448, doi: 10.3319/ TAO.2018.12.23.01. [Link]

Chen, H.-J., C.-C. Chen, G. Ouillon, and D. Sornette, 2017: Using geoelectric field skewness and kurtosis to forecast the 2016/2/6, $\mathrm{M}_{\mathrm{L}} 6.6$ Meinong, Taiwan Earthquake. Terr. Atmos. Ocean. Sci., 28, 745-761, doi: 10.3319/TAO.2016.11.01.01. [Link]

Chen, Y.-I., J.-Y. Liu, and Z.-S. Jian, 2019: Evaluation of aftershock hazard of the 2018 M 6.2 Hualien earthquake. Terr. Atmos. Ocean. Sci., 30, 411-421, doi: 10.3319/TAO.2018.12.09.01. [Link]

Dodge, D. A., G. C. Beroza, and W. L. Ellsworth, 1995: Foreshock sequence of the 1992 Landers, California, earthquake and its implications for earthquake nucleation. J. Geophys. Res., 100, 9865-9880, doi: 10.1029/95jb00871. [Link]

Dziewonski, A. M., A. Friedman, D. Giardini, and J. H. Woodhouse, 1983: Global seismicity of 1982: Centroid-moment tensor solutions for 308 earthquakes. Phys. Earth Planet. Inter., 33, 76-90, doi: 10.1016/0031-9201(83)90141-3. [Link]

Felzer, K. R., R. E. Abercrombie, and G. Ekström, 2004: A common origin for aftershocks, foreshocks, and multiplets. Bull. Seismol. Soc. Am., 94, 88-98, doi: 10.1785/0120030069. [Link]

Gutenberg, B. and C. F. Richter, 1944: Frequency of earthquakes in California. Bull. Seismol. Soc. Am., 34, 185-188.

Helmstetter, A. and D. Sornette, 2003: Foreshocks explained by cascades of triggered seismicity. J. Geophys. Res., 108, doi: 10.1029/2003JB0024009. [Link]

Hwang, R.-D., C.-Y. Lin, C.-Y. Lin, W.-Y. Chang, T.-W. Lin, Y.-L. Huang, and J.-P. Chang, 2019: Multipleevent analysis of the $2018 \mathrm{M}_{\mathrm{L}} 6.2$ Hualien earthquake using source time functions. Terr. Atmos. Ocean. Sci., 30, 367-376, doi: 10.3319/TAO.2018.11.15.01. [Link]
Jones, L. M. and P. Molnar, 1979: Some characteristics of foreshocks and their possible relationship to earthquake prediction and premonitory slip on faults. J. Geophys. Res., 84, 3596-3608, doi: 10.1029/jb084ib07p03596. [Link]

Kanamori, H., L. Ye, B.-S. Huang, H.-H. Huang, S.-J. Lee, W.-T. Liang, Y.-Y. Lin, K.-F. Ma, Y.-M. Wu, and T.-Y. Yeh, 2017: A strong-motion hot spot of the 2016 Meinong, Taiwan, earthquake $\left(\mathrm{M}_{\mathrm{w}}=6.4\right)$. Terr. Atmos. Ocean. Sci., 28, 637-650, doi: 10.3319/ TAO.2016.10.07.01. [Link]

Knopoff, L., Y. Y. Kagan, and R. Knopoff, 1982: $b$ values for foreshocks and aftershocks in real and simulated earthquake sequences. Bull. Seismol. Soc. Am., 72, 1663-1676.

Kuo-Chen, H., K.-X. Chen, W.-F. Sun, C.-W. Ho, Y.H. Lee, Z.-K. Guan, C.-C. Kang, and W.-Y. Chang, 2017: 3D Vs ambient noise tomography of the 2016 $\mathrm{M}_{\mathrm{w}}$ 6.4 Meinong Earthquake source region in Taiwan. Terr. Atmos. Ocean. Sci., 28, 693-701, doi: 10.3319/ TAO.2016.12.28.01. [Link]

Lee, Y.-T., Y.-J. Wang, C.-H. Chan, and K.-F. Ma, 2017: The 2016 Meinong earthquake to TEM PSHA2015. Terr. Atmos. Ocean. Sci., 28, 703-713, doi: 10.3319/ TAO.2016.12.28.02. [Link]

Lin, C.-H., 2009: Foreshock characteristics in Taiwan: Potential earthquake warning. J. Asian Earth Sci., 34, 655-662, doi: 10.1016/j.jseaes.2008.09.006. [Link]

Main, I. G., P. G. Meredith, and C. Jones, 1989: A reinterpretation of the precursory seismic $b$-value anomaly from fracture mechanics. Geophys. J.Int., 96, 131-138, doi:10.1111/j.1365-246x.1989.tb05255.x. [Link]

Meredith, P. G. and B. K. Atkinson, 1983: Stress corrosion and acoustic emission during tensile crack propagation in Whin Sill dolerite and other basic rocks. Geophys. J. Int., 75, 1-21, doi: 10.1111/j.1365-246x.1983. tb01911.x. [Link]

Molchan, G. M. and O.E. Dmitrieva, 1990: Dynamics of the magnitude-frequency relation for foreshocks. Phys. Earth Planet. Inter., 61, 99-112, doi: 10.1016/00319201(90)90098-i. [Link]

Molchan, G. M., T. L. Kronrod, and A. K. Nekrasova, 1999: Immediate foreshocks: Time variation of the b-value. Phys. Earth Planet. Inter., 111, 229-240, doi: 10.1016/ s0031-9201(98)00163-0. [Link]

Ogata, Y., T. Utsu, and K. Katsura, 1995: Statistical features of foreshocks in comparison with other earthquake clusters. Geophys. J. Int., 121, 233-254, doi: 10.1111/j.1365-246x.1995.tb03524.x. [Link]

Ohnaka, M., 1992: Earthquake source nucleation: A physical model for short-term precursors. Tectonophysics, 211, 149-178, doi: 10.1016/0040-1951(92)90057-d. [Link]

Omori, F., 1894: On the aftershocks of earthquakes. J. Coll. Sci. Imp. Univ. Tokyo, 7, 111-120.

Shin, T.-C., 1993: The calculation of local magnitude 
from the simulated Wood-Anderson seismograms of the short-period seismograms in the Taiwan area. Terr. Atmos. Ocean. Sci., 4, 155-170, doi: 10.3319/ TAO.1993.4.2.155(T). [Link]

Utsu, T., 1961: A statistical study on the occurrence of aftershocks. Geophys. Mag., 30, 521-605.

Wang, J. H., 1988: $b$ values of shallow earthquakes in Taiwan. Bull. Seismol. Soc. Am., 78, 1243-1254.

Wang, J. H., 1989: The Taiwan Telemetered Seismographic Network. Phys. Earth Planet. Inter., 58, 9-18, doi: 10.1016/0031-9201(89)90090-3. [Link]

Wang, J. H., 1995: Effect of seismic coupling on the scaling of seismicity. Geophys. J. Int., 121, 475-488, doi: 10.1111/j.1365-246x.1995.tb05727.x. [Link]

Wang, J. H., 2012: Some intrinsic properties of the twodimensional dynamical spring-slider model of earthquake faults. Bull. Seismol. Soc. Am., 102, 822-835, doi: 10.1785/0120110172. [Link]

Wang, J. H., 2016: A mechanism causing $b$-value anomalies prior to a mainshock. Bull. Seismol.Soc. Am., 106, 1663-1671, doi: 10.1785/0120150335. [Link]

Wang, J. H., K. C. Chen, P. L. Leu, and J. H. Chang, 2015: $b$-Values Observations in Taiwan: A Review.
Terr. Atmos. Ocean. Sci., 26, 475-492, doi: 10.3319/ TAO.2015.04.28.01(T). [Link]

Wen, Y.-Y. and C.-C. Chen, 2017: Seismicity variations prior to the $2016 \mathrm{M}_{\mathrm{L}} 6.6$ Meinong, Taiwan earthquake. Terr. Atmos. Ocean. Sci., 28, 739-744, doi: 10.3319/ TAO.2016.12.05.01. [Link]

Wen, Y.-Y., S. Wen, Y.-H. Lee, and K.-E. Ching, 2019: The kinematic source analysis for $2018 \mathrm{M}_{\mathrm{w}} 6.4$ Hualien, Taiwan earthquake. Terr. Atmos. Ocean. Sci., 30, 377-387, doi: 10.3319/TAO.2018.11.15.03. [Link]

Wessel, P. and W. H. F. Smith, 1998: New, improved version of the generic mapping tools released. Eos, Trans., $A G U, 79,579$, doi: 10.1029/98eo00426. [Link]

Wu, F. T., W.-T. Liang, J.-C. Lee, H. Benz, and A. Villasenor, 2009: A model for the termination of the Ryukyu subduction zone against Taiwan: A junction of collision, subduction/separation, and subduction boundaries. J. Geophys. Res., 114, B07404, doi: 10.1029/2008JB005950. [Link]

Wu, Y.-M. and L.-Y. Chiao, 2006: Seismic Quiescence before the 1999 Chi-Chi, Taiwan, $M_{\mathrm{w}} 7.6$ Earthquake. Bull. Seismol. Soc. Am., 96, 321-327, doi: 10.1785/0120050069. [Link] 